\title{
PERFORMANCE OF LOW RISE CONCEALED TRUSS COMPOSITE SHEAR WALLS WITH EXTERNAL COLUMNS
}

\author{
Dan Zhang ${ }^{1,2}$ - Zhong Tao ${ }^{1,2^{*}}$ - Lei Zhang ${ }^{3}$
}

\begin{abstract}
${ }^{1}$ Faculty of Civil Engineering and Mechanics, Kunming University of Science and Technology, Yunnan, Kunming, 650500, China

${ }^{2}$ Institute of Earthquake Engineering, Yunnan, Kunming, 650500, China

${ }^{3}$ Broad Homes Industrial co., Ltd, Changsha, 410000, China
\end{abstract}

\begin{tabular}{l} 
ARTICLE INFO \\
\hline Article history: \\
Received: 4.11 .2015$. \\
Received in revised form: 26.5 .2016$. \\
Accepted: 3.6 .2016$. \\
\hline Keywords: \\
Low-rise composite shear wall \\
Concealed truss \\
External columns \\
Experimental investigation \\
Finite element analysis
\end{tabular}

\section{Introduction}

Shear walls are the major structural members in reinforced concrete buildings designed to resist lateral loads. They should provide an adequate strength and sufficient ductility to avoid brittle failure under strong lateral loads during an earthquake. However, with an increase in building height, the axial compressive force at the strengthened bottom layers of the building grows quickly so that many of reinforced concrete shear walls are now weak due to an inadequate design.

\begin{abstract}
:
A review on the previous studies shows that limited analytical or experimental studies on the low-rise concealed truss shear walls with external columns under monotonic loading have already been conducted. The combination of concealed truss was welded to I-shaped steel frame and flat steel support. Two different aspect ratio composite shear walls were tested under static monotonic loading, and the failure mode, bearing capacity, ductility and stiffness were explored. A finite element model was developed and used to simulate the composite shear walls under constant axial load and lateral loading. The comparison of test results confirmed that the finite element model could predict the behavior of composite shear walls accurately. Meanwhile, stress analyses of the specimens were studied to simulate stress distribution of reinforcement, and to analyze the steel of composite shear wall with external columns at different loading stages. Taken together, this study could be a basis for developing an accurately simplified model.
\end{abstract}

Hence, for the performance of traditional RC structural walls, increasing the wall thickness is the only effective way to limit the axial load ratio if the maximum available concrete strength is restricted. Nevertheless, the excessively thick wall would not only make the construction complicated but also greatly reduce the usable floor areas. It may also result in an increase of the seismic effect. Therefore, it is difficult to obtain a reasonable and economical design when the traditional RC structural wall is applied. One effective way to address this problem is to employ new forms of structural walls that apart

\footnotetext{
* Corresponding author. Tel.: +86 13368808040

E-mail address: zhangdan@kmust.edu.cn
} 
from high bearing and deformation capacities have also acceptable wall thickness. This paper is concerned with composite shear walls that have recently developed structural walls. During the past few decades, many tall buildings all over the world have been designed with steel-concrete composite shear walls. Such composite shear walls can have the benefits of both steel and reinforced concrete shear walls, and therefore extensive investigations have been carried out into the modeling and seismic behavior. In [1], some research into composite walls with profiled steel sheeting and concrete core of approximately one-sixth scale was carried out. In [2], a novel composite shear wall system consisting of two skins of profiled steel sheeting and an infill of concrete under in-plane loading was introduced. In [3], a research program referring to a finite element analysis of steel plate shear wall (SPSW) was conducted and a steel plate shear wall model was designed. In [4], twelve specimens of highstrength concrete-filled double-steel-plate composite wall were tested under high axial compressive forces and reversed cyclic lateral loads. In [5] two parallel studies of numerical and experimental models of composite steel shear walls (CSSW) were performed. In [6], a program based on a fiber section analysis using refined material constitutive models was developed to analyze the moment-curvature behavior of concrete-filled steel plate composite shear walls. In [7], a series of quasistatic tests were conducted to investigate the lateral load-carrying capacity, deformation capacity, and energy dissipation of the steel tube-reinforced concrete (ST-RC) composite walls under the condition of high axial force ratios and cyclic lateral loading. Subsequently, in [8] seismic behaviors of six one-third scale shear walls including a usual shear wall, a shear wall with steel frame, a shear wall with steel bar truss, a shear wall with steel frame and steel bar truss, a shear wall with steel truss and a shear wall with steel and steel bar truss were carried out.

In the above studies, researchers have considered different forms of steel-concrete composite shear walls and consequently have proved that bearing capacity, ductility, and the energy dissipation capacity of composite shear walls are significantly higher than reinforced concrete shear walls. However, in the process of rapid urbanization, more and more complex high-rise buildings are in the pursuit of personalization strategies. In order to meet the requirements of architectural features, lowrise RC shear walls frequently act as the main part of lateral force resistance in the large-space bottom structures of high-rise. Once it has reached its ultimate strength under earthquake loads, brittle failure in walls is due to the rapid loss of bearing capacity, which thus proves poor seismic performance. Therefore, the low-rise RC shear wall is unacceptable in a highly seismic region. Hence, the advantage of concealed truss composite shear wall (CTSW) gradually attracts research attention. It is worth noting that the focus of most of the aforementioned studies is on the behavior of composite shear walls with embedded columns. Although external columns are very informative and provide us with more data applicable to design, it has not been enough investigated. Tests presented in [9], show that shear walls with external columns in comparison to the shear walls with embedded columns, certainly exhibited improved behavior of section bearing, deformation capacity and lateral stability. Among them, the ultimate displacement increased by half, energy dissipation capacity increased by about $20 \%$. Therefore, setting up the external columns is an important measure of efficacy in improving the seismic behavior of shear walls.

Based on [8], an innovative concealed steel truss form is proposed to make corresponding improvements: Welded I-shaped steel instead of channel steel is employed to form steel frames, and flat steel instead of the channel steel is employed to make diagonal steel bracing. This new truss form does not only effectively reduce the thickness of the shear wall, but also makes concrete more densely. The embedded steel truss could act together with concrete to form a composite shear wall. This paper explains two quasi-static tests of low-rise concealed truss composite shear walls with external columns under axial force and monotonic lateral loading conditions. The concern of this paper is to evaluate the seismic resistance of the composite wall by evaluating lateral load, deformation and stiffness variations. In addition, the focus is on nonlinear finite element analysis performed on two shear wall specimens using damage plasticity model with ABAQUS finite element package. Meanwhile, an effort has been made to analyze the stress distribution of CTSW, using finite element method as a basis for developing a (reasonable simplified) model. 


\section{Behavior of low-rise shear wall}

The actual behavior of the wall is very complex. The overall response of low-rise shear wall to loads is a combination of bending moment, shearing force and axial force. Due to gravity load from the tributary floor area and its own self-weight, wall sections are subjected to axial compression. In an actual project, shear walls are usually divided into high and low walls according to the aspect ratio or shear span ratio. Thomas N. et al [10] believed that the shear wall gave priority to bending when shear span ratio $\lambda \geq 2.0$, to shear when $\lambda<1.0$, to flexureshear mixed force when $\lambda$ was around 1.5. Definition of $\lambda$ is $\lambda=M / V h_{0}$, which reflects the ratio of the normal stress and shear stress. $\mathrm{M}$ and $\mathrm{V}$ respectively stand for bending moment and shear force; $h_{0}$ is the effective height of the shear wall cross-section. Shear span ratio $\lambda$ and aspect ratio $h_{w} / l_{w}$ ( $h_{w}$ is the height of the shear wall; $l_{w}$ is the width of the shear wall) are the same for the topbearing cantilever shear wall. Nevertheless, aspect ratio is more widely used in practice.

The shear-dominated failure mode of low-rise shear wall belongs to brittle failure that shows poor seismic performance. RC shear wall is in the elastic state before being cracked. When lateral load is applied to cracking load, bending cracks appear at the bottom of the tension side.

Loading continues to increase, cracks begin to appear diagonally on the wall plate. Along with the growth of the load, inclined cracks in the wall develop fast, whereas bending cracks at the bottom develop slowly [11]. Diagonal cracks extend to the bottom of the specimen and stop at the column inside constrained by the border column. Once the concrete of the compression zone has got brittle cracked, the longitudinal reinforcements of side columns lose the supporting effect, eventually resulting in damage of the specimen, and the failure mode known as shear failure [12].

\section{Experimental program}

\subsection{Specimen design}

To study the behavior of CTSW (concealed truss composite shear wall), an experimental program was developed in the Civil Engineering Department at the Kunming University of Science and Technology in China. Two CTSW specimens were tested, and the specimen size was designed as approximately 1:2 scale of the prototype structure owing to the loading limitation of the test machine. These specimens were an idealized representation of the bottom storey of the prototype structure. The thickness of two specimens was $125 \mathrm{~mm}$, height was $1400 \mathrm{~mm}$, and the axial compression ratio was controlled in 0.3. CTSW1 and CTSW2 were designed with different aspect ratios, being 0.93 , and 0.82 , respectively. The wallboard of both horizontal and vertical distribution reinforcement ratio was $0.3 \%$, the longitudinal reinforcement ratio on each side of the external column was $0.28 \%$. In steel truss, the cross-sectional dimension of steel beams was $150 \times 75 \times 5 \times 7$, steel column was $125 \times 60 \times 6 \times 8$, and flat steel diagonal was $50 \times 5$. Fig. 1 shows an outline and section details of the specimens.

The concrete used in the specimens was C40 (the nominal cubic compressive strength, $f_{c u, d}=40 \mathrm{MPa}$ ), and its elastic modulus was $3.25 \times 10^{4} \mathrm{MPa}$. The actual cubic compressive strength of the wall concrete tested on cubes of $150 \mathrm{~mm}$ size had the results of 46.7 MPa and 47.3 MPa for CTSW1 and CTSW2, respectively. The embedded steel truss was Q345 (the nominal yield stress, $f_{y}=345 \mathrm{MPa}$ ), and the measured yield strength was $380 \mathrm{MPa}$, and the ultimate strength was $560 \mathrm{MPa}$. The longitudinal reinforcement was HRB335 (the nominal yield stress, $f_{y}=335 \mathrm{MPa}$ ), and the stirrup was HPB235 (the nominal yield stress, $f_{y}=235$ $\mathrm{MPa}$ ). Table 1 shows these measured material properties. This study sets out to analyze concealed truss composite shear walls to obtain the failure process, carrying capacity, deformation capacity and stiffness degradation.

\section{Table 1. Measured material properties}

\begin{tabular}{|c|c|c|c|}
\hline $\begin{array}{c}\text { Rebar } \\
\text { diameter } \\
(\mathrm{mm})\end{array}$ & $\begin{array}{c}\text { Strength } \\
\text { grade }\end{array}$ & $\begin{array}{c}\text { Yield } \\
\text { strength } \\
(\mathrm{MPa})\end{array}$ & $\begin{array}{c}\text { Ultimate } \\
\text { strength } \\
(\mathrm{MPa})\end{array}$ \\
\hline 6 & HPB235 & 338 & 505 \\
\hline 8 & HPB235 & 356 & 487 \\
\hline 12 & HRB335 & 385 & 540 \\
\hline 20 & HRB335 & 420 & 574 \\
\hline
\end{tabular}



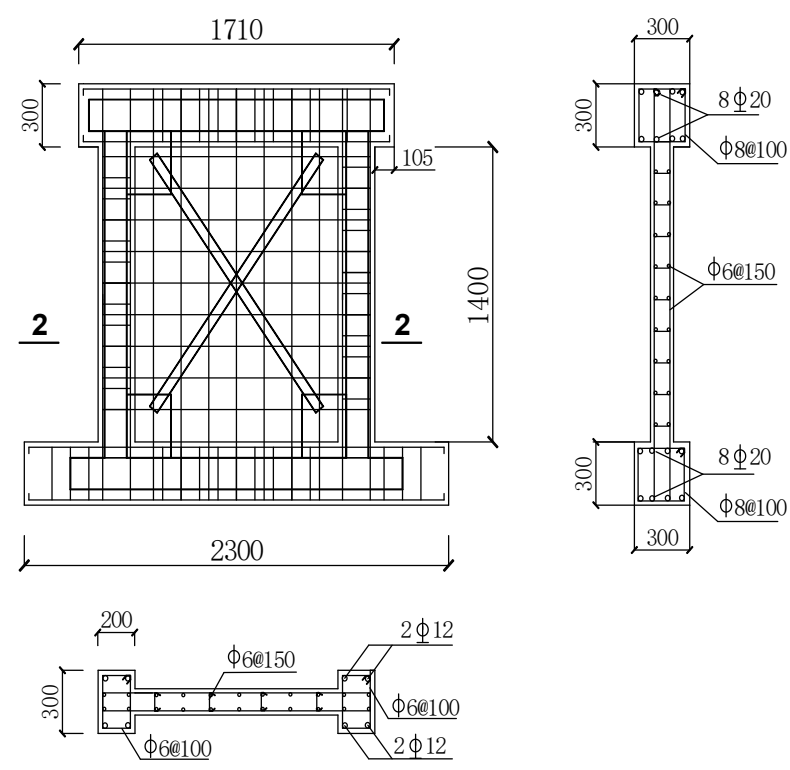

2-2

(a) CTSW1 $(n=0.93)$
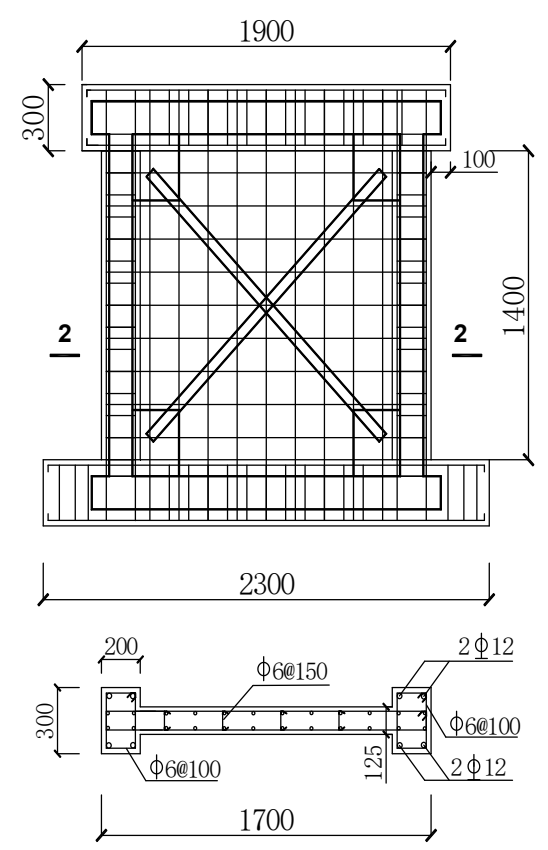

$\underline{2-2}$

(b) CTSW2 (n=0.82)

Figure 1. Details of the concealed truss composite shear walls (CTSW)

\subsection{Test set-up}

All specimens were tested under constant vertical load and monotonic in-plane lateral loading, as shown in Fig. 2. Horizontal loading point was located in the center of a top beam. Axial load provided with the vertical hydraulic jack that was connected to the rigid top-beam through a rolling support allowed the specimen to move freely in plane and enabled the axial load to be always concentric. Since the foundation was totally constrained at the bottom, the test model would also meet the fixed boundary requirements at the bottom.
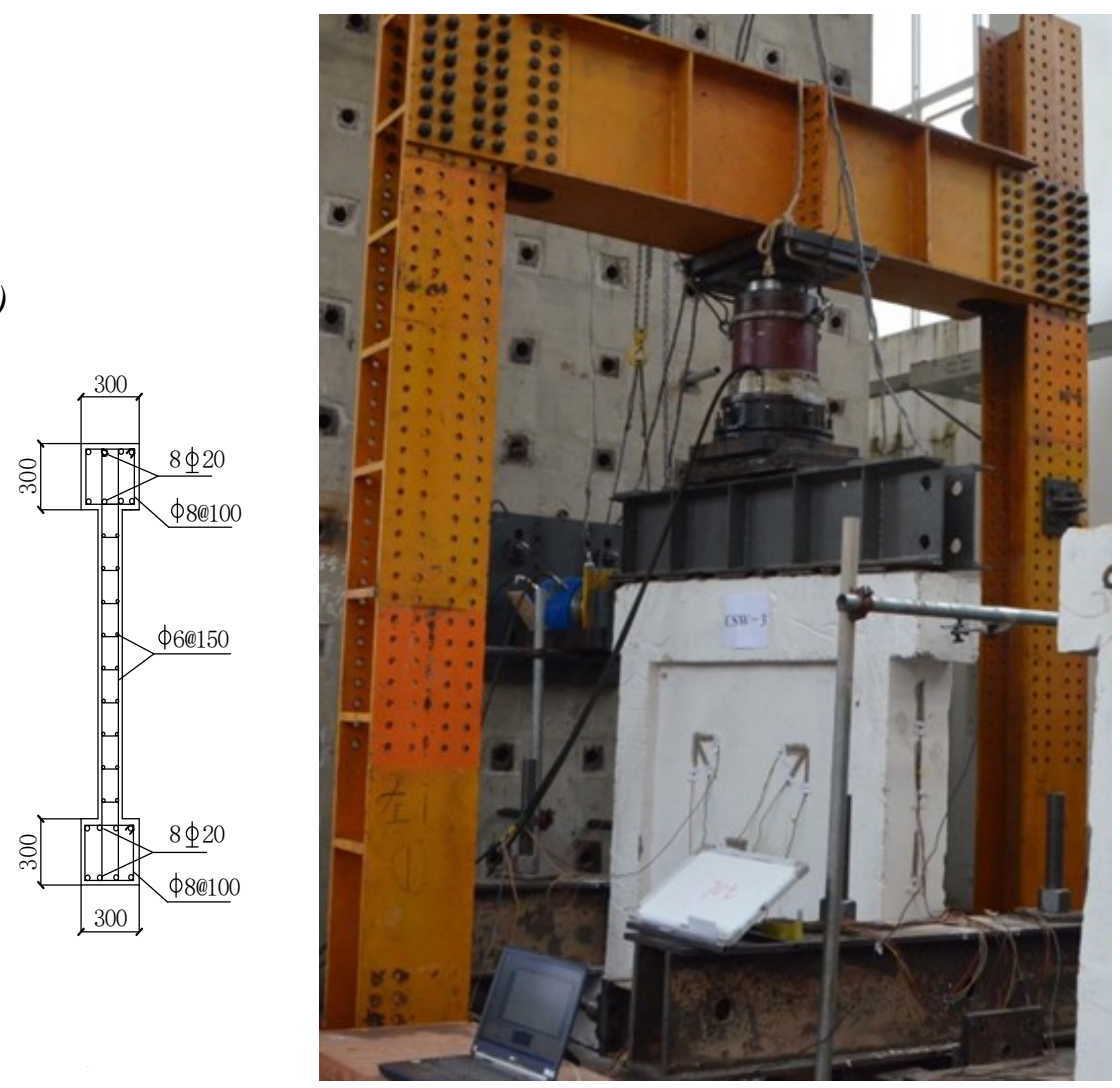

Figure 2. Test set-up

\subsection{Loading history and measurements}

There were two loading steps in the test. First, an axial compressive force was induced with a hydraulic jack (in accordance with the target axial compression ratio 0.3 ) and then it was maintained constant during loading. In turn, the lateral load was applied, and the lateral force was first controlled by load and then by top displacement. The load control was adopted before yielding, and the increment of each loading stage was $50 \mathrm{kN}$. Yield load and yield 
displacement were determined by the slope change of the horizontal force-displacement curve. After yielding the specimen, loading was triggered by increments of displacement, each being about $3 \mathrm{~mm}$. When the bottom concrete of column got cracked, displacement increased quickly so that we enlarged displacement increment to facilitate accurate recording of data. Crack load was observed after the lower end of the wall exhibited noticeable small cracks, whereas peak load was recognized as the peak point in the bearing capacity curve. During loading history, load-displacement response, strain development, and failure modes of the system also occurred. A computer aided data acquisition system was utilized to collect and record the data from strain gauges and linear displacement transducers.

\section{Test Results}

\subsection{Damage and failure mode}

During each testing under horizontal monotonic loading, the two composite walls behaved in a similar way like the behavior of low-rise shear wall described above. The specimen CTSW2 was selected to show a typical lateral force versus the top displacement in Fig. 3. In general, the damage of the specimen could be characterized by three stages: a) initial cracking stage, b) crack developing and yield stage, and c) peak load stage. Fig. 4 shows a) concrete cracking and developing, and b) crushing patterns of the specimens during tests. The damage observed at each stage was summarized as follows.

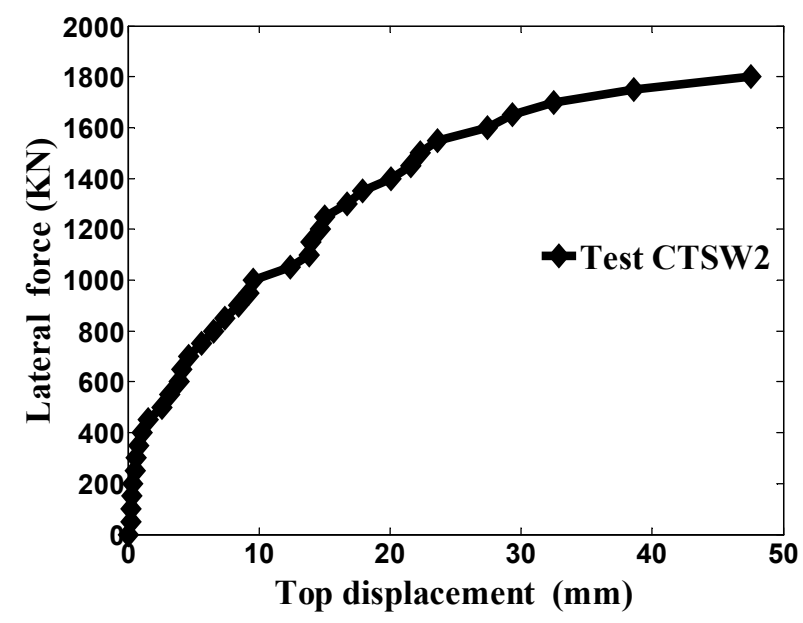

Figure 3. Lateral force versus top displacement curve for CTSW2

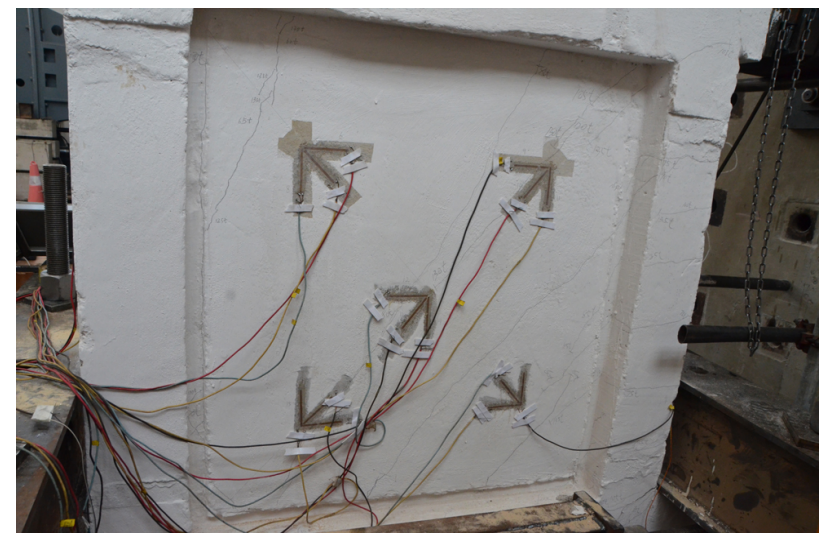

(a) Cracking pattern

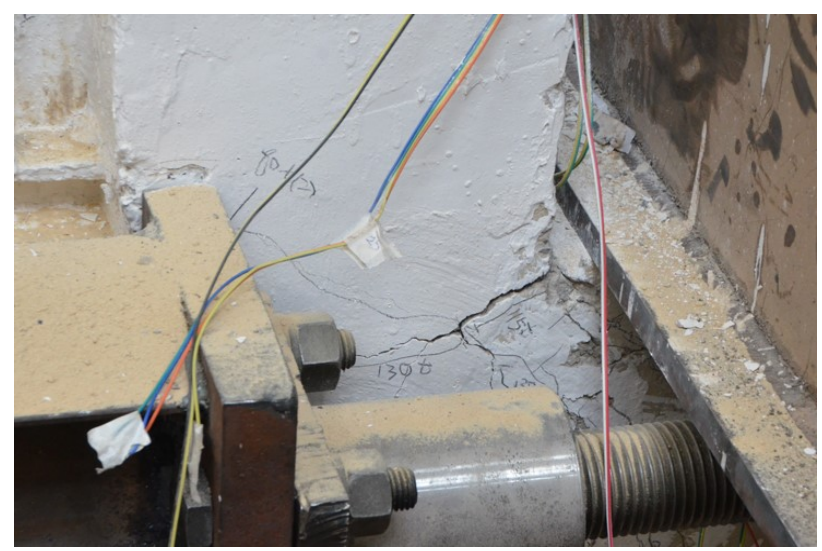

(b) Failure pattern

Figure 4. Failure Process of CTSW2

\subsubsection{Initial cracking stage}

When the load reached $33.3 \%$ of the peak load, horizontal flexural crack occurred at the bottom of column. A lower axial aspect ratio (0.82) could delay the onset of flexural cracking. As soon as the lateral load increased, cracks expanded from the edge to the wallboard and then they grew downwards. The specimen behaved nearly linearly before cracking, and the stiffness of the specimen decreased slightly after cracking.

\subsubsection{Yield stage}

This stage began from the initial cracking. When the lateral load reached $58.3 \%$ of the peak load, the specimen yielded forming a few diagonal cracks through the wall. The diagonal cracks were inclined at an approximately $45^{\circ}$ angle, and the existing 
cracks width were widened. A higher aspect ratio (0.93) could expedite the yield of vertical boundary reinforcement.

\subsubsection{Peak load stage}

In the process of displacement control, with an increase in top displacement, bearing capacity in specimen steadily increased by placing a powerful constraint on external columns. After attaining the peak lateral load, brittle crack propagation in the wall was not fully developed, but it certainly reflected the brittle nature of low-rise shear wall, and proved that external columns gave full play to binding effect. In the end, damages were mainly concentrated in the plastic hinge zone at the bottom of the shear wall. Meanwhile, the compressed concrete at the bottom of external columns got brittle cracked, and was then exposed to longitudinal reinforcement, as shown in Fig. 4 (b).

\subsection{Analysis of strength and ductility}

Table 2 presents the values of the two low-rise shear walls measured by including cracking load, apparent yielding load and ultimate load. Similarly, Table 3 shows measured values for top displacement and ductility capacity, as well as $F_{c}$ and $U_{c}$, for cracking load and cracking displacement, respectively; $F_{y}$ and $U_{y}$, respectively for the obvious yielding load and yielding displacement;

$F_{m}$ is the maximum horizontal load, $U_{m}$ is the maximum displacement corresponding to $F_{m} ; \mu_{c m}$ stands for the ratio of cracking load and ultimate load; $\mu_{y m}$ stands for the ratio of yielding load and ultimate load.

The Table 2 and Table 3 show that, for different aspect ratios of the low-rise CTSW with external columns, the bearing capacity increases with a decrease in the aspect ratio. Also, deformation capacity and ductility capacity decrease with a decrease in the aspect ratio, namely, brittleness increasingly exhibits its prominent nature

Hence, the process from obvious yielding load to the ultimate load is longer when $\mu_{y m}$ is small, namely, when the restrained yield period is longer, which is beneficial to anti-seismic effect. It can be seen from the failure mode that the novel low-rise shear walls give priority to shear failure, damages are mainly concentrated in the plastic hinge region at the bottom of the column and shear wall, and the wallboard is slightly damaged. This failure mode is to ensure the wall with a higher carrying capacity, at the same time, the deformation capacity (ultimate displacement) has no significant decline compared to [13], whose limit displacement is $47.29 \mathrm{~mm}$.

\subsection{Rigidity variation}

Fig. 5 represents the stiffness variation of the specimens by relative rigidity $\left(K_{j} / K_{\text {first }}\right)$, as a function of relative displacement $\left(\Delta_{\mathrm{j}} / \Delta_{\mathrm{y}}\right)$ where $K_{\text {first }}$ is the rigidity corresponding to before-cracking and $K_{j}$ is the rigidity corresponding to any point in the process of loading. And $\Delta_{\mathrm{y}}$ is the lateral displacement corresponding to yield load, $\Delta_{\mathrm{j}}$ is the lateral displacement corresponding to any point that is equal to $\mathrm{j}$.

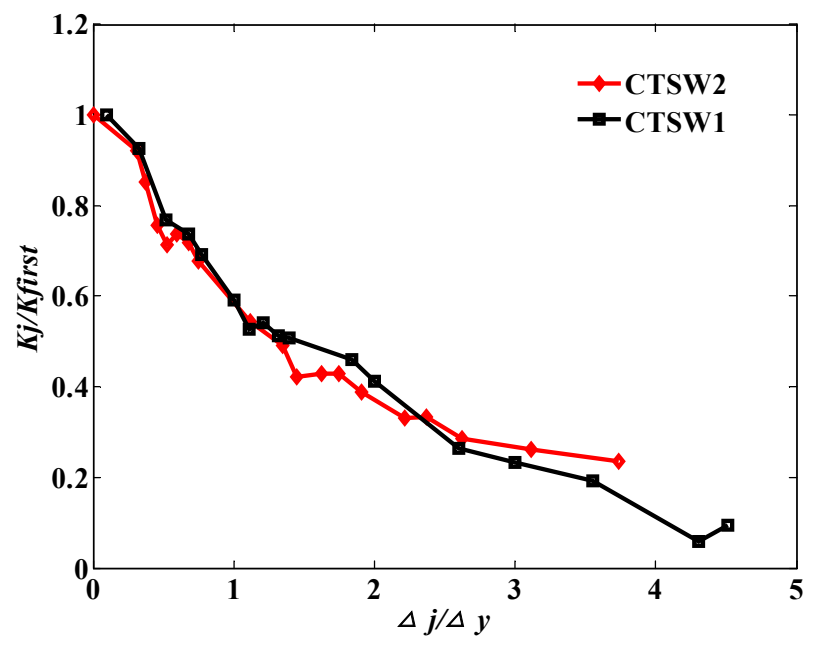

Figure 5. Rigidity variation $K_{j} / K_{f i r s t}-\Delta_{\mathrm{j}} / \Delta_{\mathrm{y}}$ relations.

The initial stiffness of shear wall largely depends on the geometry size and strength of concrete, with little effects from concealed steel truss; once the concrete has been brittle cracked, the concealed truss can not only withstand external loads, but it can also have a dowel action in concrete cracking. Therefore, the late rigidity of structure is more stable compared to conventional RC shear wall, and it is better for anti-seismic effects [13].

As it can be seen in Fig. 5, in the preliminary loading stages, the rigidity variation is almost the same for these two elements, but then the specimens have shown a little more severe rigidity degradation. The element CTSW1 exhibits relatively severe stiffness degradation, whilst the element CTSW2 exhibits less degradation. 
Table 2. Experimental results of bearing capacity of specimens

\begin{tabular}{|c|c|c|c|c|}
\hline Specimen number & $F_{c}(\mathrm{KN})$ & $F_{y}(\mathrm{KN})$ & $F_{m}(\mathrm{KN})$ & $\begin{array}{c}\mu_{c m} \\
\left(F_{c} / F_{m}\right)\end{array}$ \\
\hline CTSW1 $(n=0.93)$ & 500 & 800 & 1550 & 0.323 \\
\hline CTSW2 $(n=0.82)$ & 600 & 1050 & 1800 & 0.333 \\
\hline
\end{tabular}

Table 3. Experimental results of top displacements and ductility coefficients of specimens

\begin{tabular}{|c|c|c|c|c|}
\hline Specimen number & $U_{c}(\mathrm{~mm})$ & $U_{y}(\mathrm{~mm})$ & $U_{m}(\mathrm{~mm})$ & $\begin{array}{c}\mu \\
\left(U_{m} / U_{y}\right)\end{array}$ \\
\hline CTSW1 $(n=0.93)$ & 3.92 & 10.55 & 47.65 & 4.516 \\
\hline CTSW2 $(n=0.82)$ & 3.89 & 12.38 & 46.26 & 3.737 \\
\hline
\end{tabular}

\section{Finite elements simulation}

Since the analysis of CTSW is designed to resist earthquake loads, it is worth pointing out that it involves nonlinear material behavior and requires a special treatment and scrutiny in modelling. The finite element technique approach has been employed in recent years to model the reinforced concrete shear walls Meanwhile, though different analytical models are introduced to predict the nonlinear behavior of RC shear wall [14, 15], little effort has been devoted to the analysis of the microstress state in different development stages.

In this part, the FE model is designed within the ABAQUS 6.13 software package. For different models, an introduction of material properties is particularly important. The concrete damage plasticity model in the software is capable of modeling all types of concrete elements including beam, shell and solid. The concepts of isotropic damage elasticity are used in combination with isotropic tensile and compressive plasticity to represent the inelastic behavior of concrete. By choosing this software model, the convergence rate in the softening regime has been improved [16]. For concrete parts, the C3D8R is used, and the assigned element for the rebar is the T3D2. For profiled steel parts, C3D8R is also used. However, commercial software packages are employed for general purposes. Therefore, we need to go through several attempts to simulate composite shear walls.

\subsection{Concrete constitutive model}

Concrete stress-strain relationship is an important element of the mechanical properties of concrete, in which the stress-strain curve of concrete under uniaxial stress state is the most basic constitutive relation, and is the foundation of multiaxial constitutive model. It is the most widely used in structure analysis. In this study, the constitutive law for compression concrete is taken from Chinese code [9] as shown in Fig. 6 where the stress-strain relationship is presented as in Eqs. (1) and (2).

When $x \leq 1$,

$$
y=\alpha_{a} x+\left(3-2 \alpha_{a}\right) x^{2}+\left(\alpha_{a}-2\right) x^{3}
$$

When $x>1$,

$$
y=\frac{x}{\alpha_{d}(x-1)^{2}+x}
$$

Among them,

$$
\begin{aligned}
& x=\frac{\varepsilon}{\varepsilon_{c}} \\
& y=\frac{\sigma}{f_{c}^{*}}
\end{aligned}
$$

The concrete used is C40; $\alpha_{\mathrm{a}}$ and $\alpha_{\mathrm{d}}$ are parameter values of the ascent stage and descending stage under uniaxial compressive stress-strain curve, which are 1.90 and 1.94 , respectively; the uniaxial compressive strength of the concrete $f_{c}^{*}$ is $40 \mathrm{MPa}$; $\varepsilon_{c}$ is peak compressive strain of the concrete corresponding to $f_{c}^{*}$, which is $1790 \times 10^{-6} ; \varepsilon_{u}$ is concrete compressive strain when the stress located 
in the decline period of stress-strain full curve is equal to $0.5 f_{c}^{*} ; \varepsilon_{u} / \varepsilon_{c}$ is 2.0 .

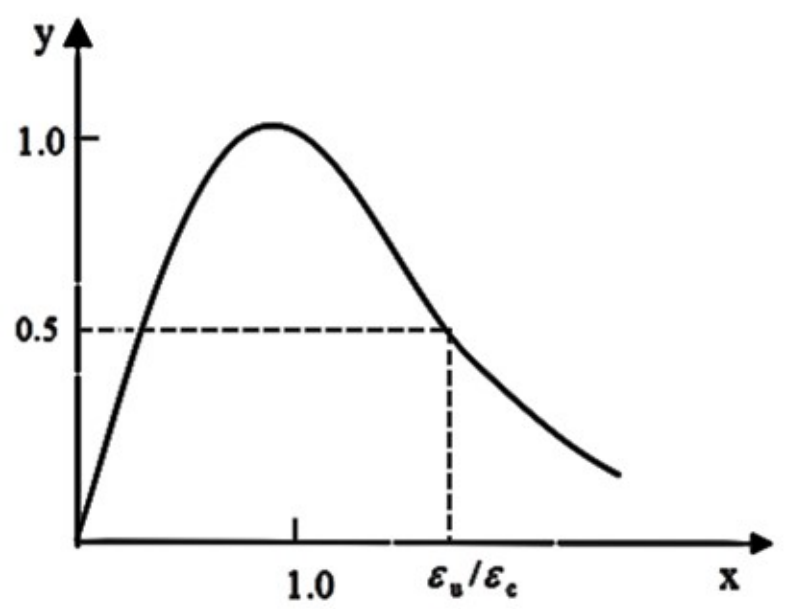

Figure 6. Uniaxial compressive stress-strain curve

The concrete uniaxial tension stress-strain curve was a smooth single-peak curve just like uniaxial compressive curve, but the shape of the curve was a little steeper. In [9], the concrete uniaxial tension stress-strain curve is shown in Fig. 7.

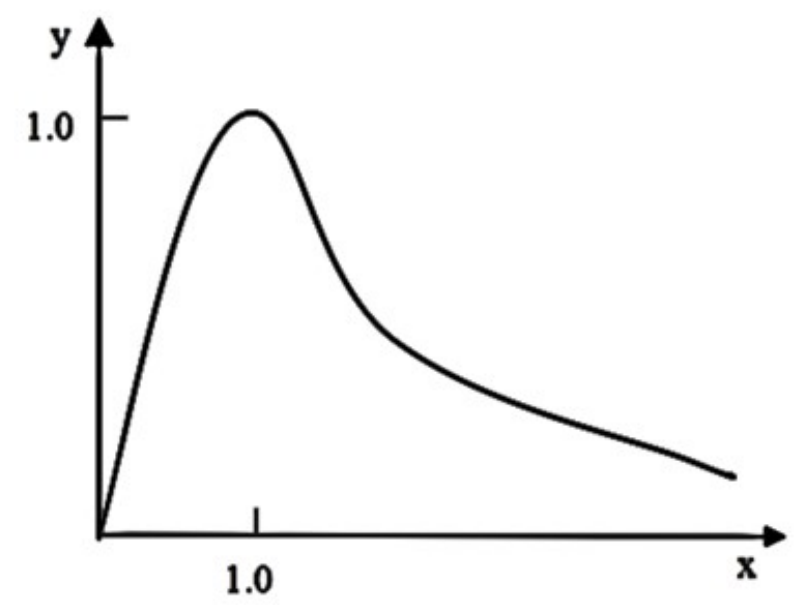

Figure 7. Concrete uniaxial tension stress-strain curve

The expression is described as follows:

When $x \leq 1$,

$$
y=1.2 x-0.2 x^{6}
$$

When $x>1$,

$$
y=\frac{x}{\alpha_{t}(x-1)^{1.7}+x}
$$

Among them,

$$
\begin{aligned}
& x=\frac{\varepsilon}{\varepsilon_{t}} \\
& y=\frac{\sigma}{f_{t}^{*}}
\end{aligned}
$$

where $\alpha_{\mathrm{t}}$ is the parameter value of descending stage under uniaxial tensile stress-strain curve, which is 0.93; the uniaxial tensile strength of concrete $f_{t}^{*}$ is $1.71 \mathrm{MPa} ; \varepsilon_{t}$ is peak tensile strain of concrete corresponding to $f_{t}^{*}$, and it is $86.88 \times 10^{-6}$.

\subsection{Reinforcement constitutive model}

Both steel bar and profile steel were bilinear models as suggested in [9], which is given in Fig. 8.

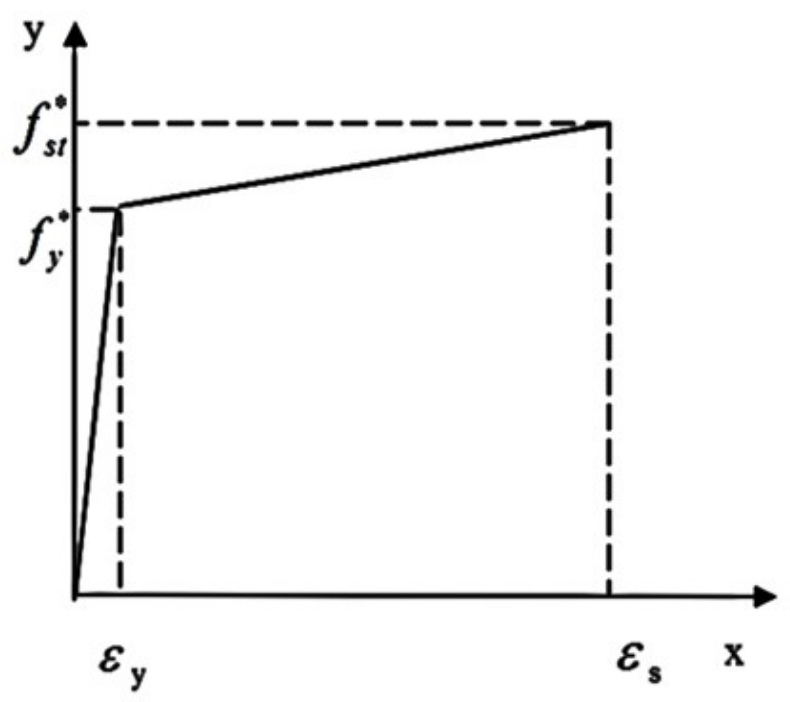

Figure 8. Uniaxial tensile stress-strain curve

The formula of reinforcement skeleton curve is expressed as:

$$
\sigma_{s}= \begin{cases}E_{s} \varepsilon_{s} & \varepsilon_{s} \leq \varepsilon_{y} \\ f_{y}^{*}+k\left(\varepsilon_{s}-\varepsilon_{y}\right) & \varepsilon_{y}<\varepsilon_{s} \leq \varepsilon_{u}\end{cases}
$$

where $\sigma_{s}$ is the stress of reinforcement; $E_{s}$ is the reinforced elastic modulus; $\varepsilon_{s}$ is the strain of reinforcement; $\varepsilon_{y}$ is the reinforced yield strain; $f_{y}^{*}$ is 
the yield strength of reinforcement; $f_{s t}{ }^{*}$ is the ultimate strength of reinforcement; $k$ is the slope of steel hardening period.

\subsection{Analysis results}

The FE constitutive model described above was used to simulate shear walls for the purpose of verification. Damage plasticity model simulated CTSWs with software and the results were compared with experimental results, as seen in Fig. 9.

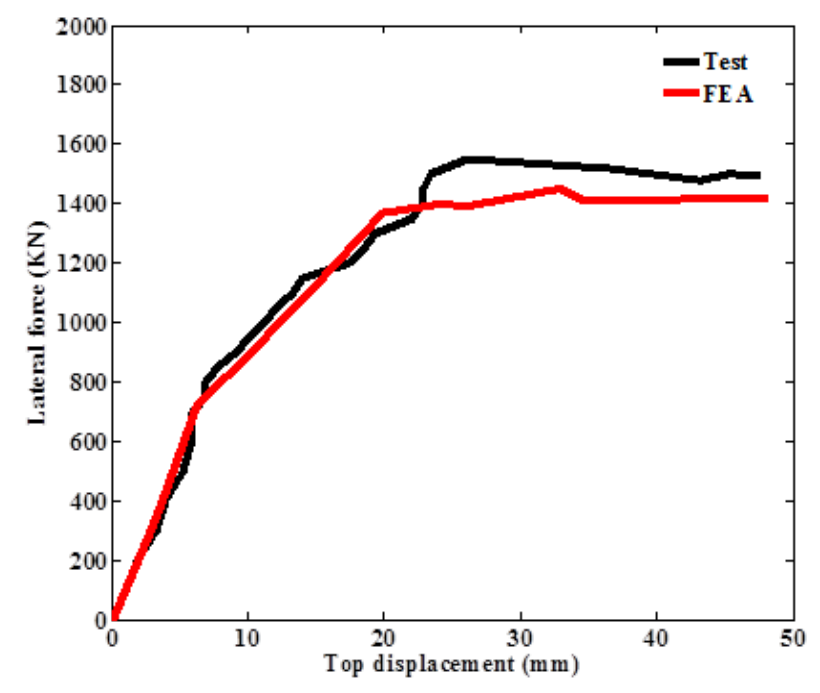

(a) CTSW1

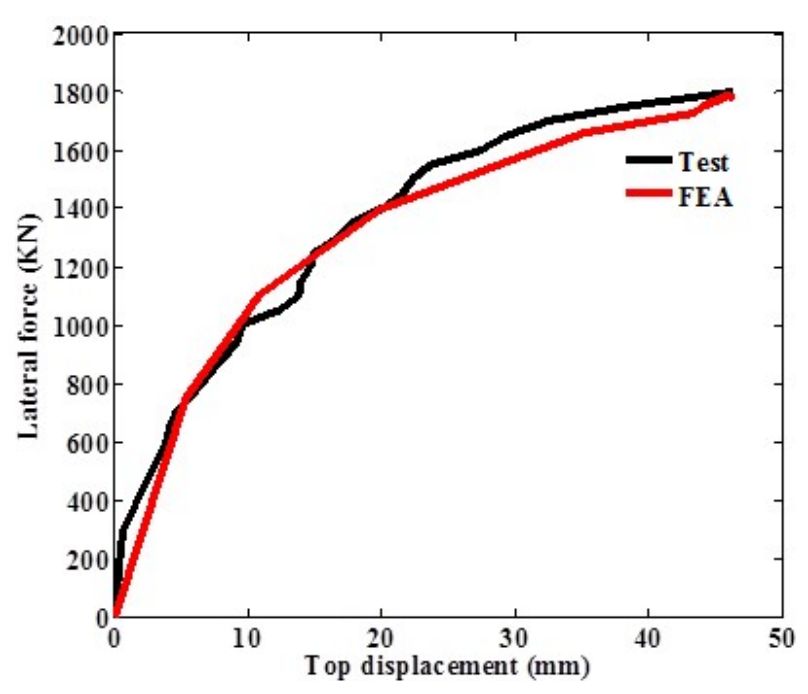

(b) CTSW2

Figure 9. Comparison of load-displacement response: test and finite element analysis (FEA)
Fig. 9 shows that cracking load and ultimate load of CTSW1 in finite element simulation are $392 \mathrm{~N}$, and $1420 \mathrm{kN}$, respectively, and the ultimate displacement is $48.22 \mathrm{~mm}$. Additionally, the cracking load and ultimate load of CTSW2 are 650 $\mathrm{kN}$ and $1800 \mathrm{kN}$, respectively, and the ultimate displacement is $47.21 \mathrm{~mm}$. Calculation results coincide well with the measured results, indicating that the established numerical model can accurately simulate the bearing capacity, deformation performance and seismic performance of shear wall under monotonic horizontal load. However, there are slight differences between the experimental and the numerical models. This is because the walls could not be modeled accurately due to the manufacturing error and idealized model. For example, differences between the distance of the concrete layer from both sides of the analytical and the tested model and the assumed bilinear behavior of the steel materials differ from their real behavior. Fig. 10 shows the stress distribution of the reinforcing bars in the wall. As the concrete got cracked, the internal load originally resisted and then it was transferred to the steel bars. The stress of distributing bars are relatively small, the maximum compressive stress is greater than the maximum tensile stress. It can be seen that the shear wall is still compression-dominant at this time; Once the lateral load has reached the yielding load, the reinforced bars yield, and the yield region is distributed along the concrete cracking zone. The horizontal distributed bars in the wall are in a tensile stress state, whereas the vertical distributed reinforcements are in tensile stress state and the transition to the compressive stress state occurs from left to right. The maximum tensile stress is distributed on the left wall, and the maximum compressive stress is distributed on the lower right side of the wall plate; After reaching the peak load, most of the vertical distributed bars at the bottom of tensile area yield, like the right side of the bottom compressive bars.

Fig. 11 shows steel truss state of Mises stress nephogram of specimen CTSW2. Once the specimen has reached the yield stage, the lower part of diagonal flat steel support yields, but the stress of the frame column is small. After entering the limit state, the bottom steel columns have blown up. The larger stress areas are distributed in diagonal steel bracing. At the same time, the stress of column base has far exceeded the yield stress. Finite element 
analysis shows that the flat steel support and steel columns, respectively, act like seismic lines improving in this way the seismic performance of the shear wall.

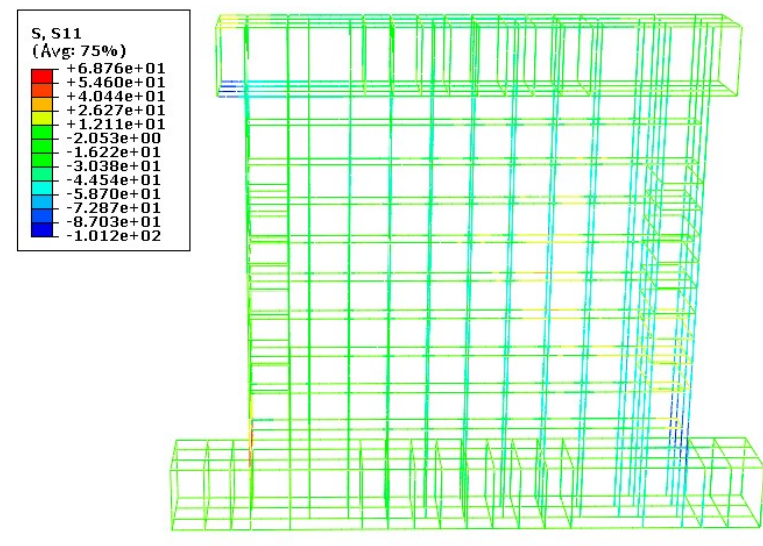

(a) Initial cracking stage

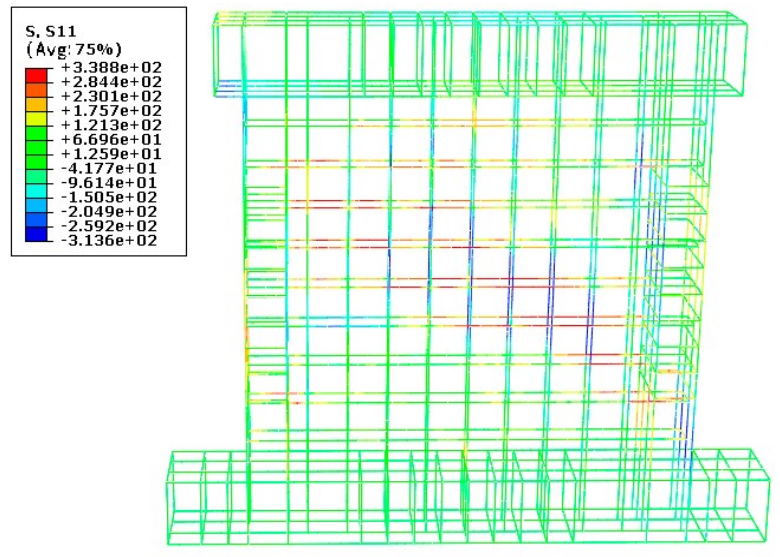

(b) Yield stage

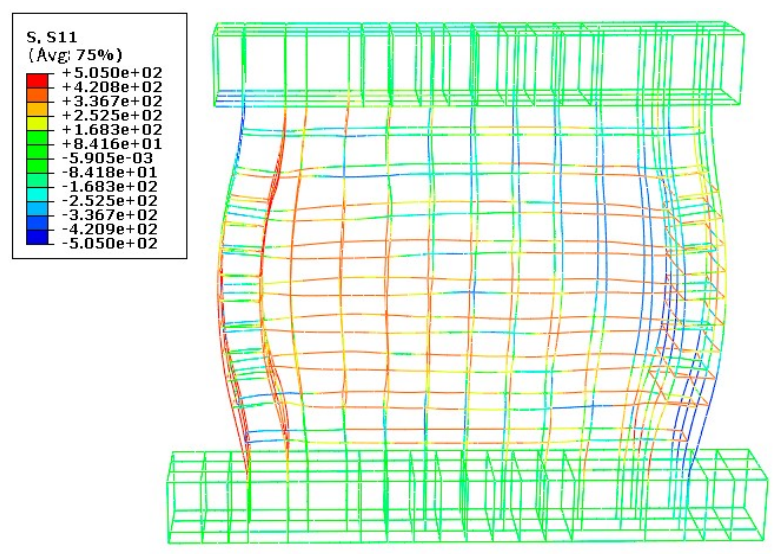

(c) Ultimate load stage
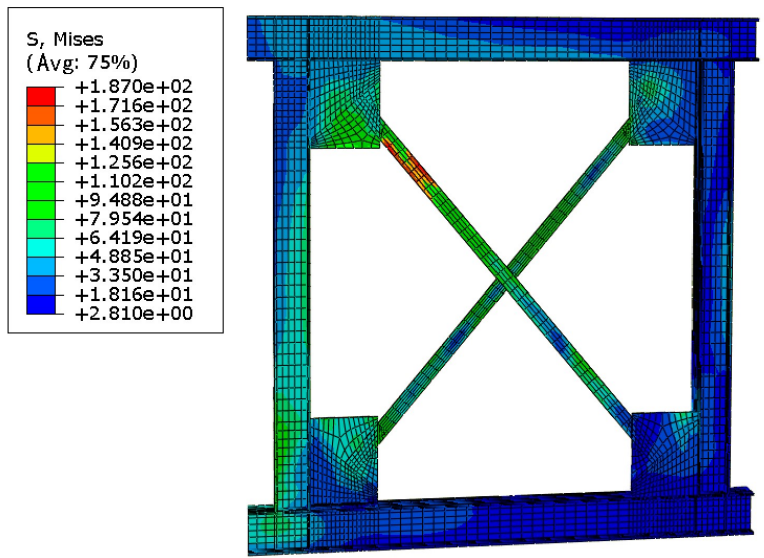

(a) Initial cracking stage
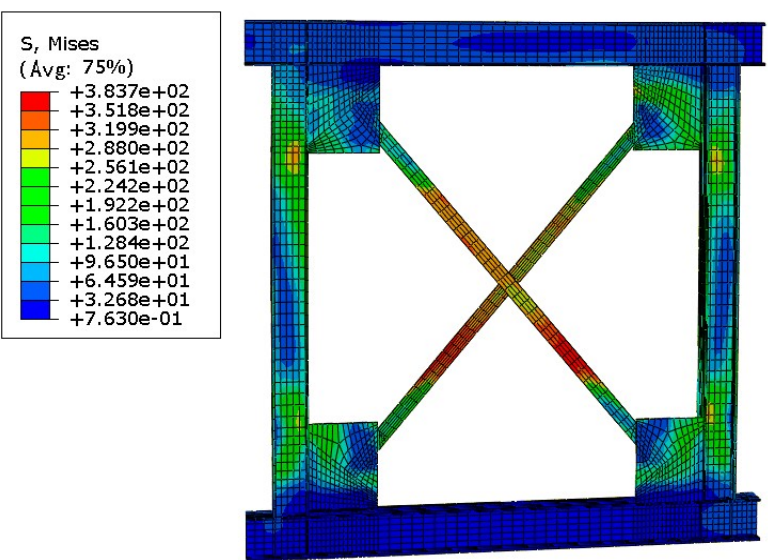

(b) Yield stage
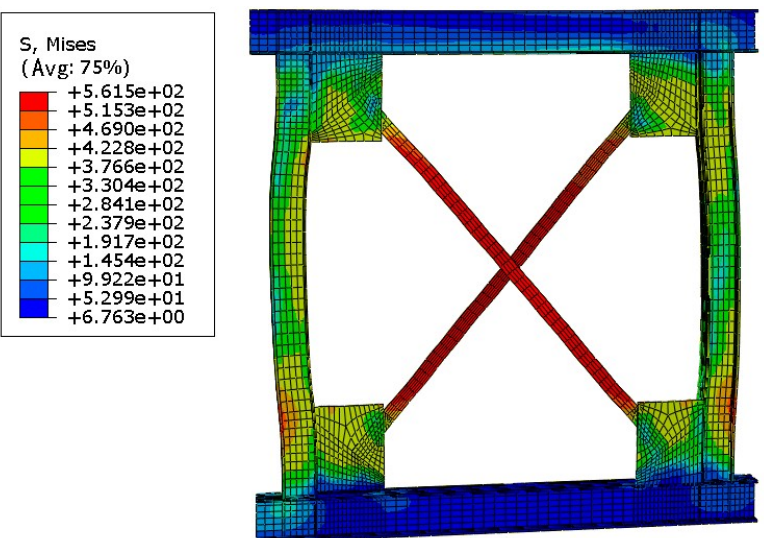

(c) Ultimate load stage

Figure 11. Truss stress distribution of CTSW2

Figure 10. Bars stress distribution of CTSW2 


\section{Conclusion}

One of the efficient methods for improving the seismic behavior of high-rise buildings is to employ the composite shear wall. A new detailed low-rise concealed truss composite shear wall (CTSW) with external columns was conceived, and two specimens with 1:2 scales were tested under axial compressive forces and monotonic lateral loads. The proposed CTSW exhibited good seismic behavior in the tests and provided a favorable choice for the bottom large-space structures of highrise. The main conclusions drawn in this research can be summarized as follows:

The series of tested CTSW exhibits a shear failure mode, when the compressed concrete in the plastic hinge region has been brittle cracked. However, cracks developed in the wall have not been fatigue cracked open beyond repair, but they only reflected the brittle nature of low-rise shear walls, and also proved that external columns have given full play to binding effect. For different aspect ratios of the low-rise CTSW with external columns, the bearing capacity is increased by decreasing the aspect ratio, and on the other hand, the deformation capacity and ductility capacity are decreased with a decrease in the aspect ratio.

The finite element model of CTSW presented in this paper shows a similar analytical behavior of the elements to the experimental investigation. Concrete damage plasticity model has been able to predict the lateral load-top displacement of a composite shear wall accurately in its linear and nonlinear stages. It shows that the finite element model can be convenient to predict the micro-stress of specimen at different stages.

Further studies are needed to extend the range of test data and to investigate other variables that have not been investigated [17]. (e.g., different axial load ratios, percentage of reinforcement, different concrete strength, number of stories would affect the performance of CTSW).

\section{References}

[1] Hossain, K.M. A., Wright, H.D..: Experimental and theoretical behavior of composite walling under in-plane shear, Journal of Constructional Steel Research, 60 (2004), 1, 59-83.

[2] Rafiei, S., Hossain, K.M.A., Lachemi, M., Behdinan, K., Anwar, M.S.: Finite element modeling of double skin profiled composite shear wall system under in-plane loadings, Engineering Structures, 56 (2013), 6, 46-57.

[3] Rahai, A.R., Alipoura, M.: Behavior and Characteristics of Innovative Composite Plate Shear Walls, Procedia Engineering, 14 (2011), 3205-3212.

[4] Nie, J.G., Hu, H.S., Fan, J.S., Tao, M.X., Li, S.Y., Liu, F.J.: Experimental study on seismic behavior of high-strength concrete filled double-steel-plate composite walls, Journal of Constructional Steel Research, 88 (2013), 206219.

[5] Rahai, A., Hatami, F.: Evaluation of composite shear wall behavior under cyclic loadings, Journal of Constructional Steel Research, 65 (2009), 7, 1528-1537.

[6] Hu, H.S., Nie, J.G., Matthew R. Eatherton.: Deformation capacity of concrete -filled steel plate composite shear walls, Journal of Constructional Steel Research, 103 (2014), 148-158.

[7] Qian, J.R., Jiang, Z., Ji, X.D.: Behavior of steel tube-reinforced concrete composite walls subjected to high axial force and cyclic loading, Engineering Structures, 36 (2012), 4, 173-184.

[8] Cao, W.L., Wang. M., Wang, S.H., Zhang, J.W., Zeng, B.: Experimental study on low-rise $R C$ shear wall with concealed truss, Journal of earthquake engineering and engineering vibration, 28 (2008), 1, 85-90.

[9] Code for seismic design of buildings $G B$ 50011-2010, China Architecture \& Building Press, Beijing, 2010.

[10] Salonikios, T.N., Kappos, A.J., Tegos, I.A., Penelis, G.G.: Cyclic Load Behavior of lowslenderness reinforced concrete walls: Design basis and test results, ACI Structure Journal, 96 (1999), 4, 649-660.

[11] Zhang, Z., Zhou, K.R.: Experimental Study on Seismic Behavior of High-Performance Concrete Shear Walls with Various Aspect Ratios, Structural Engineers, 2 (2004), 62-68. 
[12] Liu, H., Lan, Z.J., Pang, T.H, Meng, Z.P., Liu, A.L., Wen, F.: Test and Analysis on Seismic Behavior of Low-Rise steel - Encased Reinforced Concrete Shear Walls, Industrial Construction, 27 (1997), 5, 32-36.

[13] Cao, W.L., Zhang, J.W., Tao, J.P., Wang, M..: Experimental study on low-rise RC shear wall with concealed truss, Journal of southeast university, 37 (2007), 2, 195-200.

[14] Jalali, A., Dashti, F.: Nonlinear behavior of reinforced concrete shear walls using macroscopic and microscopic models, Engineering Structures, 32 (2010), 9, 29592968.

[15] Kwak, H.G., Kim, D.Y.: Material nonlinear analysis of $R C$ shear walls subject to monotonic loadings, Engineering Structures, 26 (2004), 11, 1517-1533.

[16] ABAQUS theory user manual, Version 6.13, ABAQUS Inc, 2013.

[17] Yang, Z., Zhang, Y., Chen, M., Chen, G..: Numerical simulation of ultra-strength concrete-filled steel columns, Engineering Review, 33 (2013), 3, 211-217. 